\title{
The Relevance of Religion for Political Office: Voter Bias Toward Candidates from Different Religious Backgrounds
}

\author{
Raul Madrid Jr. ${ }^{1}$ - Jennifer L. Merolla ${ }^{2}$ (D) Aldo Yanez Ruiz ${ }^{3}$. \\ Jean Reith Schroedel ${ }^{4}$
}

Accepted: 12 February 2022 / Published online: 4 March 2022

(c) The Author(s) 2022

\begin{abstract}
Over the last several decades, Gallup data shows an increased willingness among members of the public to support presidential candidates from a wide range of religious backgrounds, though a nontrivial proportion of the public is still unwilling to vote for an Atheist, Mormon, or Muslim. What underlies this opposition? We argue that voters evaluate candidates from religious out-groups more negatively on a wide range of dimensions considered desirable for political office, and that this bias should be more pronounced among the highly religious. We show support for these arguments using a survey experiment fielded with YouGov. Atheists and Muslim candidates were perceived more negatively on a large set of traits considered desirable for political office compared to candidates from religious in-groups, and Mormon candidates fall somewhere in between. The Atheist and Muslim candidates were also perceived as less competent on a diverse set of issues.
\end{abstract}

Keywords Religion $\cdot$ Candidate evaluations $\cdot$ Bias $\cdot$ Muslim $\cdot$ Atheist

Jennifer L. Merolla

merolla@ucr.edu

Raul Madrid Jr.

rmadrid23@mtsac.edu

Aldo Yanez Ruiz

aldo.yanez@norcocollege.edu

Jean Reith Schroedel

Jean.schroedel@cgu.edu

1 Mount San Antonio Community College, Walnut, USA

2 University of California, Riverside, USA

3 Norco College, Norco, USA

4 Claremont Graduate University, Claremont, USA 


\section{Introduction}

Religious diversity in the United States increased sharply after the 1965 Immigration and Naturalization Act abolished preferences for applicants from Europe. For the first time in American history, there is no single dominant religious tradition (Evans, 2009, p. 222), and the number of those who are unaffiliated with a religion has grown to almost a quarter of the population. ${ }^{1}$ Yet, legislative bodies are overwhelmingly Christian, and predominantly Protestant and Catholic. ${ }^{2}$ In fact, there are only 10 members of Congress who are Mormon, 1 with no religious affiliation, and 3 Muslim representatives in the 116th Congress (Sandstrom, 2019).

These statistics suggest that candidates from certain religious groups face an uphill battle when seeking elected office, even though the country has become more religiously diverse. Polling data from Gallup backs this inference: between 17 and $20 \%$ of the public is not willing to support a qualified Mormon for President, and the level of opposition to a Muslim candidate is $40 \%$, roughly equivalent to those unwilling to support an Atheist (Jones, 2012). Scholars have also found that voters are less likely to support Atheists, Mormons, and Muslims running for office (Benson et al., 2011; Franks \& Scherr, 2014; Lajevardi, 2020; Smith, 2014). Indeed, this is only the most recent manifestation of a long established process of boundary setting between those belonging to religious in-groups versus out-groups (Williams, 2009).

While Gallup data and existing scholarship provide evidence of bias against candidates from certain religious groups, it is not clear what is underlying that opposition. Here, we ask, in what ways bias gets manifested in evaluations of candidates from different religious traditions, especially those outside the religious mainstream. Understanding the ways in which bias operates is important since it can have implications for the strategies candidates adopt to combat bias among voters. Documenting that there is bias in voting decisions is a first step, but an important next step, which we take up here, is to understand the depth of that bias and how it operates as individuals evaluate candidates along a number of dimensions.

Drawing from Social Identity Theory, we argue that individuals create boundaries between those belonging to religious in-groups and out-groups. While in earlier points in American history, Catholic candidates were subjected to bias due to their religious faith (Slayton, 2001), as were Jewish candidates (Berinsky \& Mendelberg, 2005), in today's political climate, the dominant out-groups are Atheists, Muslims, and to a lesser extent Mormons (Calfano et al., 2013). Since individuals seek maximum distinctiveness from out-groups, we contend that candidates from groups perceived as outside the religious mainstream will be evaluated more negatively on a host of dimensions considered desirable for public office, and this will be more substantial for groups considered further outside of the mainstream. If this social identity perspective is in part what underlies negative reactions to candidates

\footnotetext{
1 http://www.pewforum.org/2015/05/12/americas-changing-religious-landscape/.

${ }^{2}$ https://www.pewresearch.org/fact-tank/2020/07/16/8-facts-about-religion-and-government-in-theunited-states/.
} 
from religious out-groups, we should find that these patterns are more pronounced among individuals who hold a stronger attachment to religion. While existing work has theorized about evaluations of religious out-groups in isolation, a social identity approach helps us to better understand commonalities in how the public evaluates religious out-groups.

We test our arguments using a survey experiment with a nationally representative sample administered to YouGov panelists. Participants were randomly assigned to evaluate a hypothetical candidate from a religious group on ten trait evaluations and assessed the candidate's ability to handle nine issues. This is the most comprehensive treatment to date in that we are looking at candidates from a broader range of religious traditions than is typical in existing scholarship, and across a wider set of evaluations, which enables us to explore whether negative evaluations of candidates from religious outgroups are confined to a small set of evaluations, or whether bias is more pervasive. We find that candidates from religious out-groups receive negative evaluations across a range of dimensions, and this effect is most pronounced among those high in religiosity.

\section{Understanding Bias Toward Candidates from Religious Outgroups}

A foundational finding from the study of public opinion and political behavior is that Americans have low levels of political knowledge (Campbell et al., 1960; Delli Carpini \& Keeter, 1996), and navigate the political world using a variety of information shortcuts. This is particularly relevant in elections, where voters are unlikely to know detailed information about all the candidates running for office, and may instead rely on other information shortcuts, such as the candidates' party labels, to help them make voting decisions (Lau \& Redlawsk, 2001). While partisanship is a dominant heuristic that voters use to navigate complex electoral choices, another important heuristic relates to features of a candidate's background or identity, which may be particularly relevant in elections where party is absent, such as in primaries or nonpartisan races.

In these settings, individuals look to other candidate characteristics to draw inferences about their qualifications, traits, and competency to handle various issues. Some characteristics are observable, like sex and race, while others may be learned through information provided on a ballot, like occupation. A candidate's religious background may fall in between. If a candidate is wearing a hijab, individuals may infer the candidate is Muslim, while it may be more difficult to discern for a Catholic candidate. Regardless of how voters learn about the characteristics of candidates, once those identities are known, how might they influence evaluations?

To provide a general theory of this process, we turn to Social Identity Theory (SIT). One important way individuals process information about various characteristics of a candidate is through their own social identities. Social Identity Theory (SIT) argues that an individual's membership in social groups affects their opinions and behavior (Hogg \& Abrams, 2007; Tajfel, 1982). For example, a person's selfimage can be tied to their race/ethnicity, nationality, partisanship, or faith. Individuals perceive the world in terms of those who belong to the same social groups (i.e., 
in-groups) and those who do not (i.e., out-groups). Generally, those who are members of the same social groups are viewed positively while those who are not are evaluated negatively, and individual members of out-groups are believed to share traits attributed to the group generally (Brown, 2000; Kinder \& Kam, 2010; Tajfel $\&$ Turner, 1979). In other words, negative stereotypes are applied to all out-group members (Allport, 1954; Dovidio et al., 1986; Fiske, 2005). This often results in a process of "enhanced group differentiation" (Greene, 2004, pg. 138). However, studies have shown that individuals do not always engage in both favoritism and derogation simultaneously, but can engage in either (Allport, 1954; Brewer, 1999). In thinking about how this translates to candidate evaluations, individuals may exaggerate the positive qualities of a candidate who they deem to be in their in-group, the negative qualities of candidates they deem to be in the out-group, or some combination of the two.

One implication of this process is that candidates who are part of out-groups may face more of an uphill battle in their quest for elected office. We focus on evaluations of candidates based on their religious background, and follow existing scholarship in characterizing Atheists, Muslims and Mormons as religious out-groups, or groups outside of the religious mainstream, (Braman \& Sinno, 2009; Kalkan et al., 2009), with the first two groups being perceived as more of an out-group than Mormons, while Catholics, Evangelicals, Mainline Protestants and Jews are considered religious in-groups, or part of the mainstream. There are several reasons why prior work has classified Mormons, Muslims, and Atheists as religious out-groups: the populations of these groups are less numerous, fewer Americans are exposed to members of these groups, they comprise only a small fraction of congressional representatives, and they are perceived less favorably by the general public (Campbell \& Putnam, 2011; Manning, 2017; Putnam \& Campbell, 2010). Scholars have documented a general bias against these candidates compared to candidates from religious in-groups (Castle et al., 2017; Lajevardi, 2020). But, how does this bias manifest itself in particular candidate evaluations? And, how pervasive is this bias in candidate evaluations? Are individuals exaggerating the negative qualities of candidates from religious out-groups on a small subset of dimensions, or on a broad range of traits and evaluations?

Existing scholarship only provides partial answers to these questions. The bulk of prior research has focused on negative evaluations of religious out-group members among the general public. For example, Muslims are perceived as violent (Sides \& Gross, 2013) and un-American (Steele et al., 2015), Atheists are considered untrustworthy (Franks \& Scherr, 2014) and hard-headed (Harper, 2007), and Mormons are perceived of as non-Christians (Penning, 2009) and less patriotic than other Americans (Smith, 2014).

What about evaluations of political candidates from religious groups? Scholars have examined the partisan stereotypes voters hold of religious groups. For example, identifying a politician as Jewish causes voters to perceive them as more liberal (Berinsky \& Mendelberg, 2005) and a plurality of Americans associate Jews with the Democratic party (Campbell and Putnam, 2011). Studies have also shown that Evangelicals are associated with the Republican party (Wlezien \& Miller, 1997) and that labeling a candidate as Evangelical raises their support among Republican 
voters (Campbell and Putnam, 2011; McDermott, 2009). Mormons are likewise tied to conservatism and the Republican party (Campbell \& Monson, 2007; Campbell and Putnam, 2011; Smith, 2014). Concerning Catholics, there has been a shift in their perceived partisanship among voters since the 1980s from Democrat to Republican (McDermott, 2007), but the overall partisan image of this group is evenly divided (Campbell and Putnam, 2011). ${ }^{3}$

Less work has considered the content of trait stereotypes of candidates from different religious groups. McDermott (2009) found that Evangelicals are perceived as particularly trustworthy, which increases voter support. Braman and Sinno (2009) found that less sophisticated individuals rate Islamic candidates as less patriotic than a generic Christian candidate. Scholars argue that voters' hesitance to cast ballots for Mormon candidates stems from perceptions among Republicans that Mormons are not truly Christians and are not trustworthy (Campbell et al., 2012). However, these studies considered a limited number of religious groups, and a small set of evaluations.

In considering how pervasive bias is toward candidates from religious out-groups, we focus on trait evaluations and perceived issue competencies, as is common in the more general literature on candidate stereotypes. We first examine a broad range of traits that are considered desirable for public office. We also consider perceptions of competency on a range of issues that voters deem important. Therefore, these are all evaluations where a candidate would want to be perceived favorably.

Since individuals seek maximum distinction between in-groups and out-groups, we expect to find that candidates from religious out-groups are evaluated more negatively than candidates from religious in-groups across a wide set of dimensions considered desirable for public office. This may particularly be the case for the groups we examine, since they comprise a small percentage of the population, people know very little about these groups (Pew Research Center, 2019), social contact with members of these groups is limited, and existing attitudes toward these groups is often negative. For example, Penning (2009) has argued that a majority of Americans possess unfavorable opinions of Atheists and Muslims, slightly favorable opinions of Mormons, and more favorable opinions towards Catholics, Jews, and Evangelical Christians. If there is a general tendency to negatively characterize religious out-groups, and individuals know very little about these groups, we would then expect trait evaluations and issue competencies to be uniformly negative for candidates from religious out-groups compared to religious in-groups:

H 1 Candidates from religious outgroups will be evaluated more negatively on character traits $(\mathrm{Hla})$ and issue competencies $(\mathrm{HI})$ than candidates from religious ingroups.

\footnotetext{
3 We do not consider ideological or partisan stereotypes in this paper since it is a different type of evaluation. It is possible that these stereotypes may impact trait evaluations and perceptions of issue competency, an important question for future research.
} 
It is also possible that the extent to which this is the case will vary among religious out-groups. Those perceived as further outside of the religious mainstream may be rated even more negatively than candidates from religious in-groups. Herberg (1983) argues that the religiousness of Americans is derived from a Judeo-Christian (i.e., Protestant, Catholic, Jewish) source. Atheists and Muslims may be perceived as furthest from the religious mainstream. Atheists are not religious at all, while Muslims are religious, but not in the Judeo-Christian tradition, and media coverage post-911 has presented many Muslims as jihadists (Steele et al., 2015). Mormons are also religious, and consider themselves Christian, but are nonNicene Christians, so they may be perceived as less outside the religious mainstream. However, scholars argue that the relative geographic isolation of Mormons, the small number of LDS members in the US ( $2 \%$ of the total population), and the lack of social interaction with other groups also contributes to their out-group status (Herberg, 1983). Consequently, we would expect a Mormon candidate to garner more positive trait assessments and perceived issue competencies compared to an Atheist or Muslim candidate, but to have lower assessments relative to in-group religious candidates. Our expectations are as follows:

H 2 Atheist and Muslim candidates will be evaluated more negatively on character traits $(\mathrm{H} 2 \mathrm{a})$ and issue competencies $(\mathrm{H} 2 \mathrm{~b})$ than candidates from other major religious groups.

H 3 Mormon candidates will be evaluated more positively than Atheist and Muslim candidates on character traits (H3a) and issue competencies (H3b) but more negatively than in-group religious candidates.

Another implication of this social identity perspective is that some subsets of individuals should be more inclined to draw distinctions between religious in-groups and religious outgroups. A characteristic that may be particularly relevant is one's level of religiosity. Scholars conceptualize religiosity as a combination of belief, belonging, and behavior (Hill \& Hood Jr., 1999). We contend that for those higher in religiosity, religion is likely an important part of their social identity. While most studies with measures of belief, belonging, and behavior do not ask about religion as a social identity, according to Pew Research, ${ }^{4}$ just over half of the US population says that their faith is an important part of their lives. We expect that individuals higher in religiosity will be more motivated to see distinctions between religious in-groups and religious out-groups and hence should perceive candidates from religious out-groups more negatively across a range of dimensions.

H 4 Voters with higher levels of religiosity will evaluate the character traits and issue competencies of candidates from religious out-groups more negatively than those low in religiosity.

\footnotetext{
4 Pew Research Center. (2020). Religion in America: US. Religious Data, Demographics and Statistics. https://www.pewforum.org/religious-landscape-study/importance-of-religion-in-ones-life/.
} 
It is of course possible, and still in line with a social identity perspective, that individuals may only perceive candidates from religious out-groups more negatively on a subset of traits or issues. That is, individuals may only exaggerate negative traits associated with the religious group a candidate identifies with. For example, since Mormons are perceived as being secretive (Smith, 2014), they may be perceived more negatively on the trait of trustworthy. While this is certainly possible, as noted above, we expect that a tendency to perceive candidates from religious outgroups negatively will be more pervasive across a range of qualities deemed desirable for public office.

\section{Study Design}

Our study was fielded by YouGov from late July to early August of 2012. After interviewing 1420 respondents, YouGov then matched the sample down to 1300 on age, gender, race, education, party identification, and ideology to be representative of the general population (see Online Appendix Table 1 for descriptive statistics on the sample).

Prior to the experiment, respondents were asked a series of demographic and attitudinal questions. Respondents were then led to a battery of questions regarding the traits and issue competencies of candidates with different religious backgrounds. We randomly assigned participants to evaluate one of seven candidates (Muslim, Jewish, Mormon, Mainline Protestant, Evangelical, Catholic, and Atheist) on these dimensions. We use this approach to limit social desirability bias, where participants might give equivalent evaluations to each individual candidate in order to avoid looking biased. This approach is commonly used in other studies that look at stereotypes with respect to gender, race, and ethnicity (e.g., Bauer, 2015; Cargile et al., 2016; Sigelman et al., 1995). Respondents were evenly distributed across experimental conditions on a range of demographic variables. ${ }^{5}$

In order to assess evaluations of candidates' traits, respondents were asked, "Thinking about the typical "(RANDOMIZE CANDIDATE: Muslim, Jewish, Mormon, Mainline Protestant, Evangelical, Catholic, Atheist)" candidate running for political office, how well do the descriptions below characterize the average "(Insert religion)" candidate? Respondents were asked whether the candidate was warm, patriotic, compassionate, moral, assertive, ethical, ambitious, rational, able to compromise, and trustworthy. Participants responded on a four-point scale from (1) not at all; (2) not too well; (3) quite well; or (4) extremely well. ${ }^{6}$

Our goal was to select a broad range of traits that are considered desirable for public office. We began by considering traits that have been found in existing work to be important to evaluations of candidates, and that are typically included in surveys. For example, integrity is a trait research consistently finds desirable in candidates

\footnotetext{
5 See Online Appendix Table 2 for balance checks. There was a slight imbalance on gender. In the robustness section, we run additional models including controls for gender, among other variables.

${ }^{6}$ We tested whether respondents were satisficing using the "respdiff" Stata package (Robmann, 2017), and did not find that it was an issue.
} 
and influential in voter evaluations (Funk, 1999; Kinder et al., 1980; Rahn et al., 1990), so we asked voters to evaluate the candidate on being ethical and trustworthy. Studies also show that morality, compassion, and empathy are traits valued by voters (Funk, 1999; Schneider \& Bos, 2011 \& 2014), so we ask participants to evaluate the candidate on being warm, moral, and compassionate. Leadership is consistently found to be an important trait that leads to more favorable evaluations of political candidates (Funk, 1999; Merolla \& Zechmeister, 2009). In our study, we use measures of agentic leadership, including ambitious and assertive, but note that while these qualities are typically perceived as positive attributes (Bauer, 2017), candidates from marginalized groups can sometimes be punished if they are perceived as too ambitious or assertive (Schneider \& Bos, 2011, 2014). Existing scholarship on religious stereotypes of candidates has considered some of these traits such as trustworthy/shady (Berinsky \& Mendelberg, 2005; McDermott, 2009), caring (Campbell et al., 2014), and moral (Harper, 2007).

We expanded beyond this set to consider traits that have been explored with respect to religious candidates. For example, some studies consider whether a candidate is perceived as patriotic (Braman \& Sinno, 2009). Others have explored traits related to being superstitious (Greeley \& Hout, 2006). Since superstitious is not considered a positive trait, we instead ask whether the candidate is rational. Other studies have looked at whether religious candidates are perceived of as argumentative/ quarrelsome (Harper, 2007), but we instead ask whether the candidate is willing to compromise, a more positive framing.

To explore whether these traits are perceived of as distinct or whether they capture an underlying construct of positive traits, we performed principal components factor analysis on all the measures. The top half of Table 1 presents the rotated factor loadings. The factor analysis revealed two factors with an eigenvalue over 1 (factor 1 eigenvalue $=6.76$; factor 2 eigenvalue $=1.13$ ). It is clear that the first factor clustered around a wide range of character traits including warm, patriotic, compassionate, moral, ethical, rational, trustworthy, and able to compromise.

The second factor clustered around only assertive and ambitious. Given the more mixed findings in the literature for agentic traits for non-traditional candidates (Bauer, 2017), and given that the factor is much weaker than the first factor (with an eigenvalue just barely over 1), for the main analyses, we focus our discussion on the first factor, and report the results for the second factor in footnotes.

After being asked about trait perceptions, respondents were asked how well the given candidate would handle a set of issues on a seven-point scale ranging from 1 to 7: foreign affairs, education, the economy, gay marriage, abortion, immigration, national security, assisting the poor, and health care. Competency both in general and on specific issues has been shown to be important for the electorate when evaluating political candidates (e.g., Kinder et al., 1980; McDermott, 2009). Pew Research (2020) and Gallup ${ }^{7}$ (2020) survey data also indicate that voters consider candidates' ability to handle these issues important. Because we are interested in exploring the depth of biases toward religious out-groups, we included a wide range

\footnotetext{
7 https://news.gallup.com/poll/1675/most-important-problem.aspx
} 
Table 1 Rotated factor loadings on traits and issue competencies

\begin{tabular}{lll}
\hline Rotated factor loadings & Factor 1 (Eigenvalue =6.76) & $\begin{array}{l}\text { Factor 2 } \\
\text { (Eigen- } \\
\text { value }=1.13)\end{array}$ \\
\hline Traits & & \\
Warm & 0.82 & 0.24 \\
Patriotic & 0.72 & 0.43 \\
Compassionate & 0.88 & 0.23 \\
Moral & 0.81 & 0.36 \\
Assertive & 0.29 & 0.87 \\
Ethical & 0.85 & 0.32 \\
Ambitious & 0.19 & 0.91 \\
Rational & 0.83 & 0.28 \\
Able to compromise & 0.85 & 0.14 \\
Trustworthy & 0.88 & 0.23 \\
\hline Issues & & Factor 1 \\
& & $($ eigen- \\
& & value $=7.09$ ) \\
\hline Foreign affairs & & 0.89 \\
Education & & 0.90 \\
Economy & & 0.91 \\
Gay marriage & & 0.81 \\
Abortion & & 0.82 \\
Immigration & & 0.92 \\
National security & & 0.92 \\
Assisting the poor & & 0.90 \\
Healthcare & & 0.92 \\
\hline
\end{tabular}

of issues. As with the trait battery, we performed principal components factor analysis (bottom half of Table 1), which revealed one factor with an eigenvalue over 1 (eigenvalue $=7.09$ ), demonstrating a pattern wherein all issue competency variables cluster around one common factor. Therefore, our analyses make use of the generated factor rather than the nine different issue competency variables, but we report the results for individual items in footnotes.

Finally, to test whether the propensity to exhibit biased evaluations towards religious out-groups varies depending on religiosity, we constructed a measure from three variables: (1) the importance of religion, measured on a 4-point scale; (2) frequency of church attendance, measured on a 6-point scale; and (3) frequency of prayer, measured on a 7-point scale. These questions are widely used to capture religiosity in the literature (Cohen et al., 2017; Gorsuch \& McPherson, 1989). They were included in the panel information provided by YouGov; therefore, the firm already had this information about participants, so we did not risk priming 
Fig. 1 Mean trait evaluations on character traits across experimental conditions, YouGov

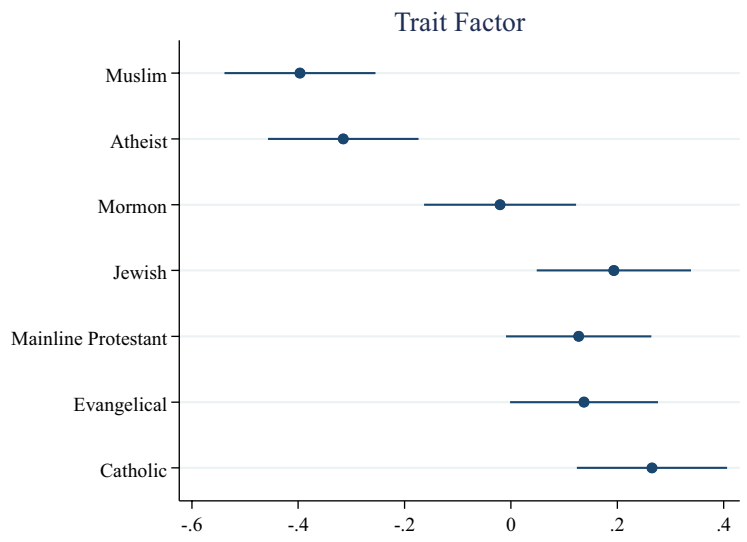

Note: $95 \%$ confidence intervals depicted and survey weights are used.

respondents about religiosity prior to the experiment. ${ }^{8}$ A principal component factor analysis on these variables revealed one factor with an eigenvalue above 1 (eigenvalue $=2.33$ ). After rotating the factor, we separated it at its median (0.187), placing those above the median at 1 , or the highly religious, and those below the median at 0 , to have enough cases in each comparison group.

\section{Findings for Trait Evaluations}

We test whether individuals hold more negative trait evaluations of candidates from religious out-groups (i.e., Muslims, Atheists, Mormons) compared to candidates from in-group faiths (i.e., Mainline Protestant (MP), Evangelical, Catholic, and Jewish) (H1a). We also test whether candidates from groups further outside the mainstream are evaluated differently ( $\mathrm{H} 2 \mathrm{a}$ and $\mathrm{H} 3 \mathrm{a}$ ). Finally, we test if voters with higher levels of religiosity evaluate the character traits of candidates from religious outgroups more negatively (H4).

Figure 1 provides the weighted mean responses on the trait factor within each experimental condition, along with $95 \%$ confidence intervals. We begin by examining the Muslim candidate. This candidate is rated poorly (mean $=-0.40$ ), and the difference in mean trait evaluations between the Muslim candidate and all others is statistically significant $(p<0.05)$, with the exception of comparisons to the Atheist candidate (mean $=-0.30$ ), who is also rated poorly. ${ }^{9}$ The pattern of results suggests a general reaction against this religious out-group, in support of H1a.

\footnotetext{
${ }_{8}$ An alternative would have been to ask questions on the strength of religious identification in the pretest, but this would have risked priming religious identity before the treatment.

9 Online Appendix Table 3 provides the weighted mean trait evaluations across experimental conditions for the individual items that make up the trait factor, while Online Appendix Table 4 provides the p-values from a series of paired difference in means tests. The findings are consistent for the individual items.
} 
Much like the Muslim candidate, the Atheist candidate is rated poorly (mean $=-0.30$ ) on the trait factor, and when comparing between groups on the factor, the differences between evaluations of the Atheist candidate and other candidates are statistically significant except when compared to the Muslim candidate $(\mathrm{p}<0.05)$, again in support of H1a. If we look at individual items that make up the trait battery, the Atheist is evaluated better than the Muslim candidate on patriotism and rational, and similar to some of the in-group candidates on rational and able to compromise (see Online Appendix Tables 3 and 4). If we turn to the final outgroup religious candidate, the Mormon candidate, while mean evaluations are lower compared to candidates from religious in-groups (mean $=0.003)$, most of these differences are not statistically significant. Specifically, the Mormon candidate is only evaluated significantly lower compared to the Catholic candidate $(p<0.05)$. If we look at the individual trait items, the Mormon candidate is rated lower on traits such as ethical, patriotic, rational, compassionate, and able to compromise, compared to some religious in-groups, but it varies depending on the comparison group (see Online Appendix Tables 3 and 4). The findings for the Mormon candidate with respect to $\mathrm{H} 1 \mathrm{a}$ are therefore more mixed. ${ }^{10}$

These findings also allow us to assess $\mathrm{H} 2 \mathrm{a}$ and $\mathrm{H} 3 \mathrm{a}$, which hold that evaluations will be most negative for the Atheist and Muslim candidates, with the Mormon candidate receiving more favorable evaluations, but still lower than religious in-groups. Recall that there were no perceived differences in trait evaluations between the Atheist and Muslim candidate, and both were evaluated more negatively than all other candidate types, including the Mormon candidate $(\mathrm{p}<0.05)$. This shows very clear support for $\mathrm{H} 2 \mathrm{a}$. This also provides partial support for $\mathrm{H} 3 \mathrm{a}$, since the Mormon candidate is evaluated more positively than both groups. However, we find only one difference between the Mormon candidate and the in-group religious candidates on the trait factor. Thus, H3a is only partially supported.

One might argue that the results are due to each of these groups being small in number in the US population, rather than being part of groups considered religious in-groups or out-groups. However, this does not seem to be the case since we do not observe bias against the Jewish candidate, a religious minority. As seen in Fig. 1, the Jewish candidate is evaluated similarly to candidates from larger religious in-groups. We also do not observe any significant differences in trait evaluations between candidates from the other religious in-groups.

Finally, we explore whether these patterns are more pronounced among those high in religiosity to test $\mathrm{H} 4$. We ran an OLS regression with dummy variables for each treatment condition, the religiosity measure, and interactions between each treatment variable and the religiosity measure (the baseline candidate was a Mainline Protestant). Because interaction terms are not directly interpretable, Fig. 2 presents the marginal effects of each experimental condition by participants' level of

\footnotetext{
10 The second factor revealed similar findings, where the Muslim and Atheist candidates were evaluated more negatively than other religious groups. See Online Appendix Fig. 1.
} 


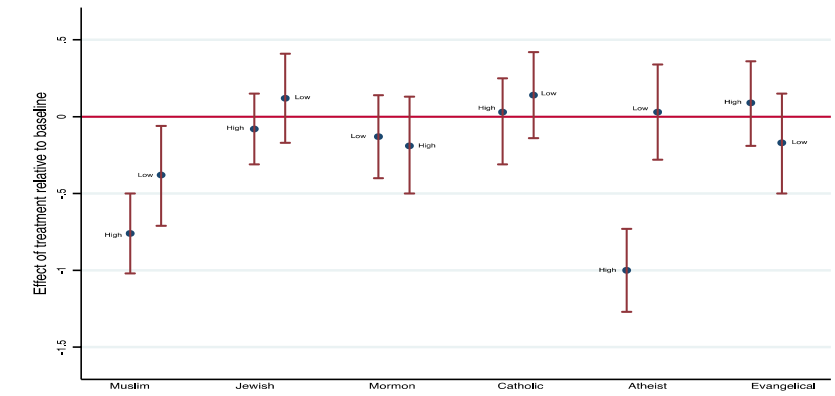

Note: $95 \%$ confidence intervals depicted and survey weights are used. The marginal effect of the treatment relative to the baseline candidate is presented by level of religiosity.

Fig. 2 Effects of treatments on candidate evaluation of character traits, by religiosity

religiosity. ${ }^{11}$ Looking first at the Muslim candidate, the marginal effects demonstrate that those low in religiosity evaluate the traits of the Muslim candidate worse $($ mean $=-0.38 ; \mathrm{p}<0.05)$ than their counterparts in the Mainline Protestant condition. However, the difference in trait evaluations is much more substantial for the highly religious (mean $=-0.76 ; \mathrm{p}<0.01$ ). Thus, the results support $\mathrm{H} 4$, in that voters with higher levels of religiosity evaluate the traits of the Muslim candidate more negatively.

Next, we turn to evaluations of the Atheist candidate. As Fig. 2 shows, the Atheist candidate is evaluated worse than the Mainline Protestant candidate among those who are highly religious (mean $=-1.00$ ), and the results are statistically significant $(\mathrm{p}<0.01)$. However, there are no significant differences in evaluations between the Atheist and Mainline Protestant candidate among those low in religiosity. These findings again lend strong support to $\mathrm{H} 4$.

With regard to how the Mormon candidate is evaluated by levels of religiosity, we do not find evidence of moderation. Those who are highly religious evaluate the Mormon candidate similarly to those low in religiosity. It is also apparent that those high in religiosity evaluate the Mormon candidate better than the Atheist and Muslim candidate, while there are no differences in evaluations across these groups among those low in religiosity. In sum, for two out of the three cases we explore, we find that those high in religiosity are more biased against religious out-groups than those low in religiosity, consistent with an SIT framework. Individuals for whom an identity is salient should seek maximum distinction between religious in-groups and out-groups. $^{12}$

Additionally, we do not observe the same type of effects in how those low and high in religiosity evaluate candidates from religious in-groups. There are no

\footnotetext{
11 For full regression results, see Online Appendix Table 5. We use Mainline Protestant as the baseline since this represents the religious background of the modal representative in Congress. The interactions between the Muslim candidate, Atheist candidate, and the religiosity index are significant $(\mathrm{p}<.10)$, which is evidence of a moderating relationship (Kam \& Franzese Jr., 2007).

12 If we run the same set of analyses on the second trait factor, measuring agentic qualities, we do not find that religiosity moderates the effect of the treatments. See Online Appendix Table 6.
} 
significant differences in how those low and high in religiosity evaluate the Jewish, Catholic, or Evangelical candidates relative to the Mainline Protestant. All of these candidates receive more favorable trait evaluations than religious out-groups.

We ran a series of robustness checks to ensure that the findings hold up to alternative specifications. First, we find that the main treatment effects and the effects for the interaction models hold up with controls for respondents' religion, partisan affiliation, ideology, age, gender, and race (see Online Appendix Tables 7 and 8). Some may wonder whether one's religious affiliation may be a substitute for intensity of religiosity - that is, perhaps particular religious traditions penalize religious out-groups more or less, rather than this being about a broad measure of religiosity. Given issues of sample size, we are only able to explore this for Evangelicals, Mainline Protestants, and Catholics. We see a similar pattern of negative reactions against the Muslim and Atheist candidate in each case, so it does not appear that the findings are confined to one denomination (see Online Appendix Tables 9 and 11). ${ }^{13}$ Ideally, we would look within denomination to see if our patterns by level of religiosity hold; however, our $\mathrm{n}$ per condition once we take into account denomination and level of religiosity becomes too small to draw any valid inferences.

Our focus has primarily been on social identity as it relates to religion. Another identity that may moderate these relationships, especially in today's politically polarized environment, is partisanship. Given the salience of religion, especially to the GOP (Pew Research Center, 2014), we may find similar patterns to what we find for religiosity. To test whether one's partisan affiliation moderates the effect of the treatments, we use partisanship as a moderator instead of religiosity (see Online Appendix Tables 12a \& 12b). Partisanship does moderate the effect of many of the treatments, but not always in the same way as religiosity. For example, Republicans negatively evaluate the Muslim and Atheist candidates, similar to those high in religiosity, but they have higher evaluations of the Mormon candidate, which we did not observe for those high in religiosity. Democrats do not penalize the Atheist or Muslim candidate, while those low in religiosity still had negative evaluations of a Muslim candidate. Furthermore, Democrats have more negative trait evaluations of the Mormon and Evangelical candidate, a pattern we did not observe among those low in religiosity. We do not have enough power to test whether religiosity matters within each partisan group, but we can bring data from another study to bear on this question. We conducted a conjoint experiment on Mechanical Turk with these same religious candidate types (among other characteristics) in 2016. In those analyses, we found that Democrats and Republicans high in religiosity were less likely to vote for the Atheist and Muslim candidates (see Online Appendix Table 13). While the dependent variable is different in this study, the results suggests that religiosity is a moderator even within each party.

\footnotetext{
13 How do those who are members of religious-outgroups react to candidates from different religious backgrounds? Our sample size of Muslims and Mormons is too small to explore reactions among these groups $(n=10$ and $n=24$, respectively). If we look at the treatment effects among those who identify as Atheists or agnostic, we do not observe negative evaluations among this group toward the Muslim or Mormon candidates, though they do have more favorable evaluations of the Atheist candidate, which is consistent with social identity theory (See Online Appendix Table 9 and 11).
} 
Fig. 3 Mean evaluations on issue competencies across experimental conditions, YouGov

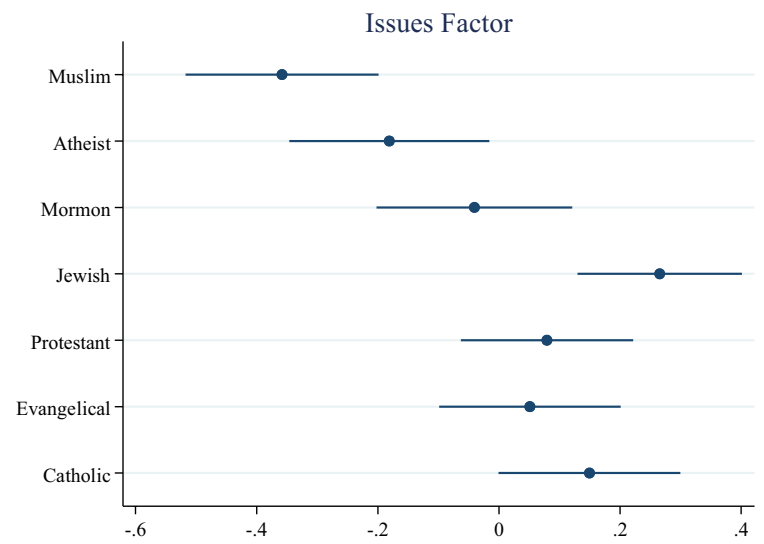

Note: $95 \%$ confidence intervals depicted and survey weights are used.

\section{Results for Issue Competencies}

We now turn to how participants in our study assessed the issue competencies of candidates from distinct faiths. Our expectations mirror our hypotheses regarding trait evaluations. In Fig. 3, we show the weighted mean on the issue competency factor across experimental conditions.

As hypothesized, respondents in our experiment rated the Muslim ( mean $=-0.36$ ), Atheist (mean $=-0.18$ ), and Mormon (mean $=-0.04$ ) politicians as the least competent at handling the range of political issues on which they were asked to judge these candidates. In fact, these were the only candidates to have negative scores on our issue competency scale. If we turn to whether these differences are statistically meaningful, the Muslim politician was rated significantly less competent than all other candidates except the Atheist $(p=0.13)$ and the latter candidate was considered less able to handle salient issues than all remaining candidates except the LDS $(p=0.23)$ office-seeker. Finally, the Mormon candidate was rated significantly less competent than only the Jewish $(p<0.05)$ and Catholic $(p<0.10)$ candidates in our study. These findings provide mixed support for H1b, since we observe lower evaluations for two out of the three religious out-groups, strong support for $\mathrm{H} 2 \mathrm{~b}$ since the Muslim and Atheist candidates are perceived of less favorably than the religious in-group candidates, and mixed support for $\mathrm{H} 3 \mathrm{~b}$, since the Mormon candidate is perceived as more competent than the Muslim, but not the Atheist candidate, and is only rated as less competent than a candidate from two religious in-groups. Again, it does not appear that the size of the group is driving these differences, since the Jewish candidate is rated as one of the most competent candidates, scoring higher than all religious out-groups, as well as significantly higher than the Evangelical $(p=0.038)$ and the Mainline Protestant $(p=0.064)$ candidates. ${ }^{14}$ Importantly, just as with trait evaluations, the Atheist candidate is perceived in a better

14 The Muslim candidate is evaluated most poorly across all individual issue competencies. 


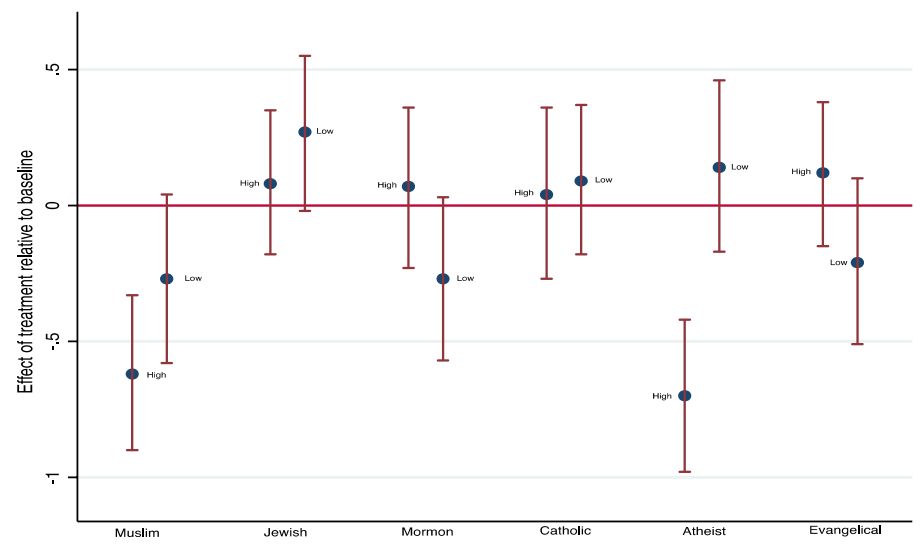

Note: $95 \%$ confidence intervals depicted and survey weights are used. The marginal effect of the treatment relative to the baseline candidate is presented by level of religiosity.

Fig. 4 Effects of treatment on candidate evaluation of issue competencies, by level of religiosity

light than the Muslim candidate on a few particular issues, including gay marriage and abortion $(\mathrm{p}<0.05$; See Online Appendix Tables 14 and 15).

Figure 4 presents the marginal effects of each experimental condition (relative to the Mainline Protestant candidate) by participants' level of religiosity (See Online Appendix Table 5 for OLS results). Consistent with $\mathrm{H} 4$, those low in religiosity rate the Muslim candidate poorly (mean $=-0.27 ; p<0.10$ ), while the highly religious evaluate said candidate even worse (mean $=-0.62 ; \mathrm{p}<0.001$ ). ${ }^{15}$ The Atheist candidate is only evaluated more poorly among those who are highly religious (mean $=-0.70)$, and the results are statistically significant $(p<0.001)$. Again, these findings lend strong support to H4. With regard to how the Mormon candidate is evaluated by levels of religiosity, we again do not find evidence of moderation. Those who are highly religious evaluate the Mormon candidate slightly better than those low in religiosity, but the differences are not statistically significant for either those low in religiosity (mean $=-0.27 ; p=0.08$ ) or high in religiosity ( mean $=0.07$; $p=0.15$ ). In sum, for two of the three cases- much like our findings with trait evaluations - we find that those high in religiosity are more biased against religious outgroups than those low in religiosity.

Adding more credence, we do not observe the same pattern in how those low and high in religiosity evaluate candidates from religious in-groups. The only significant difference we see comes from those low in religiosity assessing the Jewish candidate more favorably $($ mean $=0.26 ; p<0.10$ ). There are no significant differences in how those low and high in religiosity evaluate the Catholic or Evangelical candidate.

\footnotetext{
15 However, in Online Appendix Table 5, the interaction term between the religiosity index and the Muslim candidate is not statistically significant $(p=0.11)$.
} 
All of these politicians, including the Jewish candidate, receive more favorable issue competency evaluations than religious out-groups.

As a robustness check, we again run our analyses controlling for religion, partisan affiliation, ideology, age, gender, and race, and our main findings hold (See Online Appendix Tables 7 and 8). We also see a similar pattern of negative reactions against religious out-groups for Evangelicals and Mainline Protestants, so it does not appear that the findings are confined to one denomination (See Online Appendix Tables 10 and 11). ${ }^{16}$ As before, we analyzed whether partisanship moderates the impact of the treatment (See Online Appendix Table 12), and found a similar pattern to what we observed for trait evaluations. In short, partisanship and religiosity have some distinct effects on perceptions of candidates from different faiths. And, to refresh, in our conjoint study, we found that the conditional effect of religiosity held among Democrats and Republicans (see Online Appendix Table 13).

\section{Conclusion}

Candidates from religious out-groups often face challenges in running for political office. Our primary goal in this paper was to explore the depth of those challenges, that is how pervasive bias is against candidates from religious out-groups. One important takeaway from our theory and findings is that bias toward candidates from religious out-groups is broad and general in nature, especially among those for whom religion is a more significant part of their life. Whereas past research argues that voters hold unique stereotypes (positive and negative) about candidates based on their sex, race/ethnicity, party, etc., we drew from social identity theory to argue and show that evaluations of religious out-groups are overall negative. Attitudes on a wide range of traits and issues were strongly correlated and coalesced around only a few factors. Atheist and Muslim candidates are clearly seen as outsiders and voters paint politicians from each of these groups with broad strokes of negative attributes. For example, Rep. Ilhan Omar has been characterized as "anti-American," "anti-Semitic," and a "socialist." These negative attributions likely pose daunting challenges for such candidates winning elected office since they need to combat not just one or two stereotypes, but a range of negative evaluations. In a conjoint experiment, we find a similar pattern whereby individuals, especially those high in religiosity, are less likely to support Atheist and Muslim candidates, even when they are provided with other information about those candidates.

Our research adds to the growing body of literature on the applications of Social Identity Theory, which has roots in the discipline dating back to The American Voter, in which the authors argued that social group memberships (i.e. racial, economic, partisan, etc.) play an important role in political behavior (Campbell et al., 1960, pg. 295). More recent applications of SIT to understanding politics have

\footnotetext{
16 Similar to the findings for trait evaluations, those who identify as Atheist or Agnostic perceive the Atheist candidate as more competent at handling a range of issues (See Online Appendix Tables 10 and 11).
} 
focused on the importance of partisanship as a social identity (e.g., Greene, 1999, 2004). For example, SIT has recently been used to link Republican animosity toward minority social groups (i.e. Muslims, Blacks, Hispanics, \& LGBTQ) and support for Pres. Trump (Mason et al., 2021), as well as to explain negative \& positive feelings toward political parties in the US (Bankert, 2020) and Europe (Bankert et al., 2017). However, our study demonstrates that SIT is also a useful theoretical framework for understanding how voters evaluate, and choose between, candidates from different religious faiths and why they exhibit bias toward those from religious out-groups.

Still, while there seems to be bias across the board against Muslim and Atheist candidates, our results nevertheless show a few particular traits and issue competencies where an Atheist candidate may differentiate themselves from other out-groups. For example, an Atheist candidate may wish to highlight their rationality, and may wish to make gay marriage and abortion more salient political issues, especially in electoral contests where they are pitted against other out-group candidates.

As discussed above, Mormons are evaluated more favorably than Atheists and Muslims, but on average as lower than in-group candidates on trait evaluations. However, many of the differences relative to in-group candidates were not significant. Furthermore, the Mormon candidate does just as well as in-group religious candidates on perceived competence in handling different issues. Together, these findings suggest that Mormon candidates have gained wider acceptance. This may in part be linked to the high-profile presidential candidacy of Mitt Romney in 2012, though he faced hurdles running for President because of his faith (Campbell et al., 2012). In contrast to some of the patterns for Muslims and Atheists, those higher in religiosity sometimes had higher evaluations of the Mormon candidate compared to those low in religiosity.

Our findings help explain why Atheists and Muslims are underrepresented in political office, while Mormons fare quite a bit better. As noted, there are currently only three Muslims serving in Congress, no open Atheists, and only 10 members of the LDS Church. The higher representation of members of Mormons in Congress is also likely related to their geographical concentration in certain states. The number of candidates from religious out-groups who succeed in winning office should increase over time as the proportion of Americans who are not religiously affiliated continues to grow. Furthermore, Atheist and Muslim candidates should perform better in Democratic primary elections, where there are fewer highly religious voters than there are in Republican primaries, and where voters may care about some of the issues Atheist candidates do well on.

Our findings also suggest that candidates from in-group faiths should highlight their religious affiliation when facing rivals from religious out-groups as they will be evaluated more positively by comparison. This is especially true in races with a majority or plurality of highly religious voters. The religious affiliation of candidates can also play a significant role in non-partisan local elections, open primaries, and general elections in which candidates can draw from highly religious voters from both major parties. In these races, where party identification does not serve as a useful heuristic for voters, a candidate's religious affiliation can have a more substantial effect. Moreover, the findings with respect to positive evaluations of Jewish candidates suggest that perceptions of a religious minority can improve over time. The 
findings for the Mormon candidate in this study suggest that perceptions may be shifting in this direction, though Atheist and Muslim candidates still face challenges, especially among the highly religious.

There are already signs of shifts in religious attachment today compared to when our data was collected in 2012. At present, the proportion of Americans with no religious affiliation is $26 \%$ overall, and $34 \%$ of Democrats identify as religious "nones" (Pew Research Center, 2019; for a scholarly treatment of the causes and consequences of this increase, see Campbell et al., 2020). These numbers have increased since our experiment was conducted, so the depth of bias may have diminished somewhat over time. However, only $16 \%$ of Republican have no religious affiliation and almost $80 \%$ identify as Christian. In terms of overall evaluations, Muslims recently scored a 48 on a feeling thermometer question, while Atheists received a rating of 50 and Mormons were graded at 54. While perceptions of these groups have improved since our data was collected, these groups are still ranked lower than all other religious groups and a majority consider Islam to be outside of "mainstream American Society" (Pew Research Center, 2017). Furthermore, our conjoint experiment was conducted during the 2016 elections and supports the conclusions drawn from our original study (see also Lajevardi, 2020). In other words, we expect that candidates from religious out-groups still face an electoral disadvantage when running against candidates from religious in-groups across a range of dimensions.

Supplementary Information The online version contains supplementary material available at https://doi. org/10.1007/s11109-022-09782-6.

Materials Availability Replication materials for this manuscript can be accessed on the Political Behavior Dataverse: https://doi.org/10.7910/DVN/XV8GCK.

Open Access This article is licensed under a Creative Commons Attribution 4.0 International License, which permits use, sharing, adaptation, distribution and reproduction in any medium or format, as long as you give appropriate credit to the original author(s) and the source, provide a link to the Creative Commons licence, and indicate if changes were made. The images or other third party material in this article are included in the article's Creative Commons licence, unless indicated otherwise in a credit line to the material. If material is not included in the article's Creative Commons licence and your intended use is not permitted by statutory regulation or exceeds the permitted use, you will need to obtain permission directly from the copyright holder. To view a copy of this licence, visit http://creativecommons.org/licen ses/by/4.0/.

\section{References}

Allport, G. W. (1954). The nature of prejudice. Addison-Wesley Publishing Company.

Bankert, A. (2020). Negative \& positive partisanship in the 2016 U.S. presidential elections. Political Behavior, 43(4), 1467-1485.

Bankert, A., Huddy, L., \& Rosema, M. (2017). Measuring partisanship as a social identity in multi-party systems. Political Behavior, 39, 103-132.

Bauer, N. M. (2015). Emotional, sensitive, and unfit for office? Gender stereotype activation and support female candidates. Political Psychology, 36(6), 691-708.

Bauer, N. M. (2017). The effects of counterstereotypic gender strategies on candidate evaluations. Political Psychology, 38(2), 279-295.

Benson, B. V., Merolla, J. L., \& Geer, J. G. (2011). Two steps forward, one step back? Bias in the 2008 presidential election. Electoral Studies, 30, 607-620. 
Berinsky, A. J., \& Mendelberg, T. (2005). The indirect effects of discredited stereotypes in judgments of Jewish leaders. American Journal of Political Science, 49(4), 845-864.

Braman, E., \& Sinno, A. H. (2009). An experimental investigation of causal attributions for the political behavior of muslim candidates: Can a muslim represent you? Politics and Religion, 2, 247-276.

Brewer, M. B. (1999). The psychology of prejudice: Ingroup love or outgroup hate? Journal of Social Issues, 55(3), 429-444.

Brown, R. (2000). Social identity theory: Past achievements, current problems \& future challenges. European Journal of Social Psychology, 30, 745-778.

Calfano, B. R., Friesen, A., \& Djupe, P. A. (2013). Mitigating mormonism: Overcoming religious identity challenges with targeted appeals. PS: Political Science \& Politics, 46(3), 562-568.

Campbell, A., Converse, P. E., Miller, W. E., \& Stokes, D. E. (1960). The American voter. The University of Chicago Press.

Campbell, D. E., \& Monson, J. Q. (2007). Dry kindling: A political profile of American mormons. In Matthew Wilson, J. (Ed.), From pews to polling places: Faith and politics in the American religious Mosaic (pp. 105-130). Georgetown University Press.

Campbell, D., Geoffrey, C., \& Green, J. C. (2020). Secular surge: A new fault line in American politics. Cambridge University Press.

Campbell, D., Green, J. C., \& Quin Monson, J. (2012). The stained glass ceiling: Social contact and Mitt Romney's "religion problem." Political Behavior, 34, 277-299.

Campbell, D., Green, J. C., \& Quin Monson, J. (2014). Seeking the promised land: Mormons \& American politics. Cambridge University Press.

Campbell, D. E., \& Putnam, R. D. (2011). America's grace: How a tolerant nation bridges its religious divides. Political Science Quarterly, 126(4), 611-640.

Cargile, I. A. M., Merolla, J. L., \& Schroedel, J. R. (2016). "Intersectionality and Latino/a candidate evaluation. In S. Navarro, S. L. Hernandez, \& L. A. Navarro (Eds.), Latinas in American politics (pp. 39-60). Lexington Books.

Castle, J. J., Campbell, D. E., Layman, G. C., \& Green, J. C. (2017). Survey experiments on candidate religiosity, political attitudes, and vote choice. Journal for the Scientific Study of Religion, 56(1), 143-161.

Cohen, A. B., Mazza, G. L., Johnson, K. A., Enders, C. K., Warner, C. M., Pasek, M. H., \& Cook, J. E. (2017). Theorizing \& measuring religiosity across cultures. Personality \& Social Psychology Bulletin, 43(12), 1724-1736.

Delli Carpini, M. X., \& Keeter, S. (1996). What americans know about politics \& why it matters. Yale University Press.

Dovidio, J. F., Evans, N., \& Tyler, R. B. (1986). Racial stereotypes: The contents of the cognitive representations. Journal of Experimental Social Psychology, 22(1), 22-37.

Evans, J. H. (2009). Where is the counterweight? Explorations of the decline in mainstream protestant participation in public debates over values. In S. Brint \& J. R. Schroedel (Eds.), Evangelicals and democracy in America religion and society (pp. 221-248). Russell Sage Foundation.

Fiske, S. T. (2005). Social cognition and the normality of prejudgment. In J. F. Dovidio, P. Glick, \& L. A. Rudman (Eds.), On the nature of prejudice: Fifty years after allport (pp. 36-53). Blackwell Publishing.

Franks, A. S., \& Scherr, K. C. (2014). A sociofunctional approach to prejudice at the polls: Are atheists more politically disadvantaged than gays and Blacks? Journal of Applied Social Psychology, 44, 681-691.

Funk, C. L. (1999). Bringing the candidate into models of candidate evaluation. The Journal of Politics, 61(3), 700-720.

Gallup. (2020). Several issues tie as most important in 2020 Election. https://news.gallup.com/poll/ 276932/several-issues-tie-important-2020-election.aspx.

Gorsuch, R. L., \& McPherson, S. E. (1989). Intrinsic/extrinsic measurement: I/E-revised and single-item scales. Journal for the Scientific Study of Religion, 28(3), 348-354.

Greeley, A., \& Hout, M. (2006). The truth about conservative Christians: What they think \& what they believe. The University of Chicago Press.

Greene, S. (1999). Understanding party identification: A social identity approach. Political Psychology, 20(2), 393-403.

Greene, S. (2004). Social identity theory \& party identification. Social Science Quarterly, 85(1), 136-153.

Harper, M. (2007). The stereotyping of nonreligious people by religious students: Contents and subtypes. Journal for the Scientific Study of Religion, 46(4), 539-552.

Herberg, W. (1983). Protestant-Catholic-Jew: An essay in American religious sociology. Anchor.

Hill, P. C., \& Hood, R. W., Jr. (1999). Measures of religiosity. Religious Education Press. 
Hogg, M. A., \& Abrams, D. (2007). Intergroup behavior \& social identity. In M. A. Hogg \& J. Cooper (Eds.), The SAGE handbook of social psychology. SAGE Publications Inc.

J Jones (2012). Atheists, muslims see most bias as presidential candidates. Gallup. Retrieved from http:// www.gallup.com/poll/155285/atheists-muslims-bias-presidential-candidates.aspx. Accessed 8 Nov 2021.

Kalkan, K. O., Layman, G. C., \& Uslaner, E. M. (2009). "Band of others?” Attitudes toward muslims in contemporary American society. The Journal of Politics, 71(3), 847-862.

Kam, C. D., \& Franzese, R. J., Jr. (2007). Modeling and interpreting interaction hypotheses in regression analysis. University of Michigan.

Kinder, D. R., \& Kam, C. D. (2010). Us against them: Ethnocentric foundations of American opinion. The University of Chicago Press.

Kinder, D. R., Peters, M. D., Abelson, R. P., \& Fiske, S. T. (1980). Presidential prototypes. Political Behavior, 2(4), 315-337.

Lajevardi, N. (2020). Outsiders at home: The politics of American islamophobia. Cambridge University Press.

Lau, R. R., \& Redlawsk, D. P. (2001). Advantages \& disadvantages of cognitive heuristics in political decision making. American Journal of Political Science, 45(4), 951-971.

JE Manning (2017). Membership of the 115th Congress. Congressional Research Service.

Mason, L., Wronski, J., \& Kane, J. V. (2021). Activating animus: The uniquely social roots of trump support. American Political Science Review, 115, 1508-1516.

McDermott, M. L. (2007). Voting for catholic candidates: The evolution of a stereotype. Social Science Quarterly, 88(4), 953-969.

McDermott, M. L. (2009). Religious stereotyping and voter support for evangelical candidates. Political Research Quarterly, 62(2), 340-354.

Merolla, J. L., \& Zechmeister, E. J. (2009). Terrorist threat, leadership, \& the vote: Evidence from three experiments. Political Behavior, 31, 575-601.

Penning, J. M. (2009). Americans' views of muslims and mormons: A social identity theory approach. Politics and Religion, 2, 277-302.

Pew Research Center. (2014). Religious landscape study. https://www.pewforum.org/religious-landscapestudy/party-affiliation/. Accessed 8 Nov 2021.

Pew Research Center. (2017). U.S. muslims concerned about their place in society but continue to believe in the American dream. https://www.pewforum.org/2017/07/26/findings-from-pew-research-centers2017-survey-of-us-muslims/. Accessed 8 Nov 2021.

Pew Research Center. (2019). What Americans know about religion. https://www.pewforum.org/2019/07/23/ what-americans-know-about-religion/. Accessed 8 Nov 2021.

Pew Research Center. (2020). Religion in America: U.S. religious data, demographics and statistics. https:// www.pewforum.org/religious-landscape-study/importance-of-religion-in-ones-life/. Accessed 8 Nov 2021.

Putnam, R. D., \& Campbell, D. E. (2010). American grace: How religion divides \& unites us. Simon \& Schuster Inc.

Rahn, W. M., Aldrich, J. H., Borgida, E., \& Sullivan, J. L. (1990). A Social-cognitive model of candidate appraisal. In J. A. Ferejohn \& J. H. Kuklinski (Eds.), Information and democratic processes (pp. 136159). University of Illinois Press.

Robmann, J. (2017). RESPDIFF: Stata module for generating response differentiation indices (Version: 1.0) [Computer Software]. Boston College.

A Sandstrom (2019). 5 Facts about the religious makeup of the 116th congress. Pew Research Center.

Schneider, M. C., \& Bos, A. L. (2011). An exploration of the content of stereotypes of black politicians. Political Psychology, 32(2), 205-233.

Schneider, M. C., \& Bos, A. L. (2014). Measuring stereotypes of female politicians. Political Psychology, $35(2), 245-266$.

Sides, J., \& Gross, K. (2013). Stereotypes of muslims \& support for the war on terror. The Journal of Politics, 75(3), 583-598.

Sigelman, C. K., Sigelman, L., Walkosz, B. J., \& Nitz, M. (1995). Black candidates, white voters: Understanding racial bias in political perceptions. American Journal of Political Science, 39(1), 243-265.

Slayton, R. A. (2001). Empire statesman: The rise and redemption of Al Smith. Free Press.

Smith, D. T. (2014). The Mormon dilemma: How old and new religious divides hurt Mormon candidates in the United States. Electoral Studies, 35, 283-291. 
Steele, R. R., Parker, M. T., \& Lickel, B. (2015). Bias within because of threat from outside: The effects of an external call for terrorism on anti-muslim attitudes in the United States. Social Psychological \& Personality Science, 6(2), 193-200.

Tajfel, Henri, \& Turner, J. C. (1979). an integrative theory of intergroup conflict. In V. Worchel \& W. G. Austin (Eds.), The social psychology of intergroup relations. Brooks Cole.

Tajfel, H. (1982). Social psychology of intergroup relations. Annual Review of Psychology, 33, 1-39.

Williams, R. (2009). Politicized evangelicalism and secular elites creating a moral other. In S. Brint \& J. R. Schroedel (Eds.), Evangelicals and democracy in America: Religion and politics (pp. 143-178). Russell Sage Foundation.

Wlezien, C., \& Miller, A. H. (1997). Social groups \& political judgments. Social Science Quarterly, 78(3), $625-640$.

Publisher's Note Springer Nature remains neutral with regard to jurisdictional claims in published maps and institutional affiliations. 